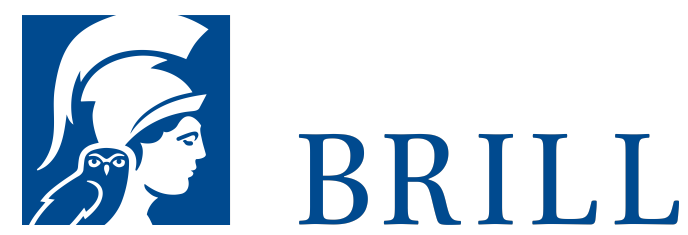

\title{
Geschichte der ästhetischen Bildung
}

Band 1: Antike und Mittelalter

Authors:Jörg Zirfas, Leopold Klepacki, Eckart Liebau, and Johannes Bilstein

Die Geschichte der ästhetischen Bildung erscheint in 4 Bänden und steht bis zum Erscheinen des 4. Bandes zur Subskription! Mit diesem vierbändigen Werk zur Geschichte der ästhetischen Bildung wird eine schmerzliche Lücke in der Geschichte der Bildung und der Pädagogik geschlossen. Die Beschäftigung mit Kunst, Schönheit, Spiel und Form hat in allen Epo-chen der europäischen Geschichte zentrale Bedeutung für die Bildung des Menschen. Ästhetische Bildung war und ist dabei immer eng mit künstlerischer Produktion und ästhetischer Rezeption sowie mit Nachahmung und Kreativität verbunden. Die Darstellung ist in vier Zeitabschnitte gegliedert: Antike und Mittelalter, Frühe Neuzeit, Neuzeit und Moderne. Die zentralen Autoren werden jeweils unter biographischen und inhaltlichen Aspekten behandelt; die jeweilige Theorie ästhetischer Bildung wird im Grundriss dargestellt. Kulturwissenschaftliche Einführungen eröffnen jeweils Autoren übergreifend einen historischen Rahmen für Lebensformen, Weltanschauungen, Bildungskonzepte und ästhetische Modelle der einzelnen Epochen.

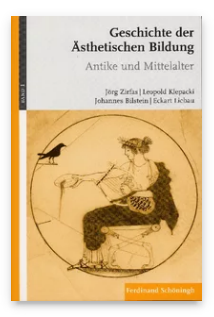

Pages: 243

Seiten

Language:

German

Subjects:

General,

Education

Publisher: Brill |

Schöningh

Series:

Geschichte der ästhetischen

Bildung, Volume: 1

E-Book (PDF)

Released online: $\mathrm{O} 2 \mathrm{Mar} 2 \mathrm{O} 2 \mathrm{O}$

ISBN: 978-3-

657-76492-1

List price

Paperback

Publication date: 22 Jul 2009

ISBN: $978-3-$ 506-76492-8

List price 
For more information see brill.com

Order information: Order online at brill.com +44330 333 0049 | customerservices@brill.com Submission information: brill.com/authors

Titles published by Brill | Fink, Brill | mentis or Brill | Schöningh: +49(o)715413279216| brill@brocom.de 